\title{
Article
}

\section{Cooperative actors in domestic abuse and their association with prosecution: implications for the criminal justice system}

Birdsall, Nathan, Kirby, Stuart and Phythian, Rebecca

Available at http://clok.uclan.ac.uk/33777/

Birdsall, Nathan ORCID: 0000-0002-7253-9211, Kirby, Stuart ORCID: 00000002-3049-1248 and Phythian, Rebecca ORCID: 0000-0001-6423-2116 (2020) Cooperative actors in domestic abuse and their association with prosecution: implications for the criminal justice system. The Police Journal: Theory, Practice and Principles. ISSN 0032-258X

It is advisable to refer to the publisher's version if you intend to cite from the work. http://dx.doi.org/10.1177/0032258×20931922

For more information about UCLan's research in this area go to http://www.uclan.ac.uk/researchgroups/ and search for <name of research Group>.

For information about Research generally at UCLan please go to http://www.uclan.ac.uk/research/

All outputs in CLoK are protected by Intellectual Property Rights law, including Copyright law. Copyright, IPR and Moral Rights for the works on this site are retained by the individual authors and/or other copyright owners. Terms and conditions for use of this material are defined in the policies page. 


\title{
Cooperative Actors in Domestic Abuse and their Association with Prosecution: Implications for the Criminal Justice System
}

\author{
Nathan Birdsall \\ Stuart Kirby \\ Rebecca Phythian
}

University of Central Lancashire, Preston, UK.

\begin{abstract}
Suggestions to increase prosecution rates in domestic abuse cases often focus on improving victim cooperation and evidence gathering. This study explores the impact of persons involved in abuse investigations by modelling five variables (victim cooperation; witness cooperation; presence of children; suspect admission; and presence of physical evidence) across 540 cases of domestic abuse. The presence of physical evidence, as well as victim and witness cooperation, all increased the likelihood of a charge against the suspect. However, suspect confession often resulted in a police caution, meaning no successful charge. The implications of these findings to improve investigation and prosecution are discussed.
\end{abstract}

\section{KEY WORDS:}

Domestic abuse, intimate partner violence, suspect charging, victim engagement. 


\section{INTRODUCTION}

Domestic abuse is considered a problem in many countries across the world, with police forces criticised in relation to recording practices, officer responses and victim support (Eigenberg et al., 2012; HMICFRS, 2017). This concern also includes the lack of prosecution, even though many police agencies and jurisdictions have a policy of positive action.

Within the UK, Her Majesty's Inspectorate of Constabulary (2014) conducted a critical thematic review of crime recording practice and made recommendations to improve the recording and investigation of domestic abuse. This included a requirement for police forces to provide an explanation when a prosecution was not instigated. Subsequently, whilst the Crime Survey of England and Wales suggests that the prevalence of abuse has remained constant, police records showed an increase of $23 \%$ for the year ending March 2018 compared to the year before (a total of 599,549 recorded cases) (ONS, 2018). Therefore, it is believed that crime recording has improved following the data integrity inspections, as police reports are more consistent with the estimates derived from victim surveys (MOPAC, 2018).

With increased police recording, however, investigative issues have become more apparent. In terms of arrest rates, national police data illustrated that, on average, arrests were made in 38 cases out of every 100 reported (ONS, 2018). In their report on case outcomes, the Home Office (2018) discovered that UK domestic abuse prosecutions (charges/summons) dropped from 18\% in 2017 to $15 \%$ in 2018. The national review found that 'evidential difficulty' was the most likely reason for this, highlighting the rise in evidential difficulty disposals from $42 \%$ in 2017 to $47 \%$ in 2018 . In essence, the rise is believed to be linked to the fact that more complex crimes are recorded, such as cases concerning victim non-cooperation and historical reports, which result in a higher level of non-prosecution (Home Office, 2018; MOPAC, 2018). A key issue within forming responses to domestic abuse, therefore, is how to bring more perpetrators to justice given the rise in evidential difficulty cases (CPS, 2017). As Davis et al. (2003) explain, enhanced investigation can add substantially to the cost and level of resources associated with the 
inquiry, meaning that this approach suffers from practical difficulties at a time when police resources are declining (UNISON, 2018). This study aims to explore these issues in more detail, specifically exploring the importance of actor cooperation in relation to charging a suspect for a domestic abuse crime.

\section{LITERATURE REVIEW}

Whilst many police forces support 'positive action' in domestic abuse cases, this term often remains ambiguous and is directed by individual discretion on a case-by-case basis (Barlow \& Walklate, 2018). Often, a multitude of decisions are required, including: whether the behaviour can be interpreted as domestic abuse; which legislation is most appropriate for arrest; and the most appropriate way for the case to progress (Myhill \& Johnson, 2015). In this process, frontline officers are said to form simplistic 'schemas', use 'street craft', or 'working rules' to formulate a personalised framework for interpreting events, people, and situations (Robinson et al., 2018). Due to the diverse and complex nature of domestic abuse cases, investigations focus heavily on evidence gathering; this includes the use of tactics such as body-worn video (Morrow et al., 2016) or encouraging victim cooperation for photographs and testimony (Peterson \& Bialo-Padin, 2012). Unfortunately, as domestic abuse is a crime that often occurs behind closed doors, many cases can reveal limited evidence and result in a situation of "he said, she said" (Hartley, 2001, p.510). This often means charges are not sought by investigators or prosecutors, who require the presence of legal factors such as seriousness, strength of evidence, and culpability of the suspect (O'Neal et al., 2015). Indeed a U.S. study by Rauma (1984) found that District Attorneys simplified the prosecutorial decision-making approach by saying strong cases have "good victims and bad offenders, good evidence, and are serious enough to warrant attention from authorities" (p.384). This creates significant limitations in responding to abuse. This is because emphasis on physical abuse with injury, evidenced through photographs or body worn video (Ellis et al., 2015), only responds to the core 'violent incident model' (Stark, 2012). Consequently, there is a risk that deeper issues may be overlooked, such as coercive control and re-victimisation as highlighted by Barlow and Walklate (2018). 
Studies also show police reliance on victim cooperation to progress the case and charge the suspect (Dawson \& Dinovitzer, 2001). O’Neal et al. (2015) highlight that victim cooperation is the most important factor in arrest and prosecution decision-making, which Tyler and Fagan (2008) suggest is predominantly due to the increased legitimacy of such complaints. Victim cooperation enables the police to build a strong case by collecting a detailed account of the incident and harvest, where available, further supporting evidence (Hamby et al., 2016). However, this approach places emphasis on the victim's testimony being able to discredit the suspect's version of events, especially when it comes to court proceedings (Lifschitz, 2004). Subsequently, Regoeczi and Hubbard (2016) argue that victim retraction is one of the biggest impediments to a successful investigation and prosecution. It is further argued that this issue can be cyclical in nature, as police and prosecutors' assumptions of victim non-cooperation at the outset of a case could cause some victims to disengage (Belknap et al., 2010). Consequently, the mutual tension between criminal justice administrators and victims of abuse reflects the constant challenge when trying to persuade victims to cooperate with prosecutions (Starmer, 2011). To overcome this issue in the UK, there has been a habitual use of witness summons to place a legal obligation on the victim to give evidence at court (Porter, 2018).

However, summonsing victims to cooperate ignores the core problem, which is that victims and the police can often have different aims. Whilst the police aim to prosecute the suspect, Hoyle and Sanders (2000, p.21) explain that the ultimate aim of the victim is to get "the violence to stop". Furthermore, Menaker and Cramer (2012, p.424) highlight the compounded burden of being a "victim-witness" to a crime, as providing testimony in court has the potential to cause further trauma and stress to the victim. These conflicts can sometimes lead to difficulties in engagement, as some officers may prioritise the witness role to secure evidence for a prosecution, rather than focusing on the needs of the victim (Barrett \& Hamilton-Giachritsis, 2013). As such, Birdsall et al. (2017) highlight how victims may not desire a prosecution in each case, as it may not necessarily empower them to handle their situation and achieve their aim of becoming abuse free. This is because it may generate, or exacerbate, other personal issues such as financial difficulty, the loss of 
housing, or upheaval within the family unit (Carey \& Soloman, 2014), as well as stress caused by interacting with the criminal justice process (Robinson \& Cook, 2006).

Due to these complexities, Ellison (2002) argues that the pressure of prosecution should be removed from victims wherever possible. In order to achieve this goal, however, improvements are needed in the police response to understand how a wider approach, that is an approach based around other actors, could benefit the case. Whilst previous research highlights how suspect and victim characteristics have smaller and less consistent associations with charging decisions (Johnson \& Dai, 2016), there is little understanding around the extent to which each present and cooperative individual impacts the likelihood of a successful charge against a domestic abuse perpetrator.

Whilst the UK definition of domestic abuse presents the issue as including only those directly involved (Callaghan et al., 2015), that is intimate partners or family members, there are a wider array of individuals who can be present, involved, and/or suffer harm in abuse cases. These individuals can either cooperate with the police investigation, potentially strengthening it, or provide no supporting information. Instances of noncooperation can include the victim and/or witness failing to provide a statement to officers (Sleath \& Smith, 2017), as well as a suspect who provides no explanation for the incident (Peterson \& Bialo-Padin, 2012). Understanding the involvement of other actors in incidents of abuse can also be helpful in identifying additional means of supporting the victim. This is especially pertinent as Fanslow and Robinson (2010) found that $40 \%$ of victims from New Zealand stated they received no help from friends after reporting their abuse. It is therefore useful to summarise the limited literature available, which outlines the potential influence of each actor in charging domestic abuse perpetrators.

Firstly, the suspect and their interaction with the police, victim and evidence can often influence the progression of an investigation. Police officers are likely to focus on a suspect's demeanour in each case of abuse, whereby an inappropriate attitude could trigger suspicions of guilt. This can include visible aggression (Dawson \& Holton, 2014) as well as a 'flat' and unemotional demeanour throughout the investigation (Douglass et al., 2016). Robinson et al. (1994) have argued that the expected and appropriate response to appear 
credible within an investigation is visible distress. In such circumstances, both suspects and victims would be expected to be emotional, but not aggressive, to appear credible within the initial stages of an investigation (Dawson \& Holton, 2004). Further, the suspect's demeanour in responding to the evidence also influences the case. Whilst Peterson and Bialo-Padin (2012) found that suspect statements were useful in increasing the rate of prosecution, the suspect may also present a statement to effectively circumvent the evidence presented. An effective counter-narrative could mean that the suspect avoids the threshold of a realistic prospect of conviction required for prosecution in the UK (Hartley, 2001). This may be more likely in cases of domestic abuse, since incidents often occur within private residences involving intimate partners. The suspect can use this familiarity to explain injuries to the victim through alternative narratives, such as the victim's injuries were self-inflicted, the suspect was acting in self-defence, rough sex, or historical injuries.

Secondly, the presence of children can also influence the progression of a case. The profound negative impact that domestic abuse has on children is well documented within academic literature, with McCormick et al. (2018) explaining how exposure to a parent's arrest forms key Adverse Childhood Experiences (ACEs). In addition, Callaghan et al. (2015, p.1552) further argue that in cases of coercive control, the very nature of the abuse means that child witnesses should be classified as "direct victims" alongside the abused partner. However, whilst the added vulnerability may increase seriousness from a practitioner and police perspective, it may not have the same effect on the family unit. Studies reveal that victims may prioritise children in their decision making (Kelly, 2009), but may be unaware, or underestimate, the extent to which witnessing abuse can cause harm (Peled \& Gil, 2011). Emphasising the role of children in cases of abuse does not necessarily guarantee victim cooperation, as some victims withdraw their assistance due to reasons pertaining to childcare (Rhodes et al., 2011), or the belief that social services do not understand their position (Hines \& Douglas, 2009). Difficult decisions about protection must be made within cases involving children, especially when there is victim retraction. Consequently, some US jurisdictions have previously enforced 'failure to protect' policies, which aim to remove children from the family unit to guarantee their safety (Trepiccione, 
2000). From a policing perspective, however, research highlights how some officers may not take responsibility for children involved in the incident unless they are physically injured or have directly witnessed the incident (Millar et al., 2018). Therefore, as recognition of the child's trauma in abuse incidents increases, officers and prosecutors may take cases involving children more seriously, which may lead to a greater likelihood of suspect charging.

Thirdly, in addition to the immediate family unit, a range of third-parties may become involved with cases of abuse. These include friends, family, neighbours, and even complete strangers. Friends and family may be helpful to victims of abuse by providing material and emotional support without fear of stigmatisation (Liang et al., 2005), which is likely to have a positive impact upon victim engagement. The dynamic becomes especially helpful when the third-party acts as an advocate for the victim by providing their witness testimony as the main source of evidence, thus removing the burden from the victim (Ellison, 2002).

Whilst third-party involvement may be beneficial to the victim, all witnesses of abuse are vital to the police when they provide supporting accounts and evidence as part of the investigation. Witnesses can aid the police at the initial scene, and those who corroborate the victim's account tend to bolster the credibility of the complaint (Dawson \& Holton, 2014). Hamby et al. (2016) further explain that this has a compounded positive impact when friends of the aggrieved partner also suffer abuse from the suspect. The credibility of these cases can be strengthened when the victim and victim's friends file complaints which are consistent and complimentary. Whilst important in cases involving physical abuse, their presence and cooperation would become more important in cases of non-physical abuse. This is because they may have the capacity to attest to the suspect's behaviour, which may involve threats, surveillance, restraints, humiliation or other tactics (Cook \& Goodman, 2006). Therefore, gaining insight into the context of the relationship is often key to understanding the abuse (Dutton \& Goodman, 2005). Unfortunately, little effort has been placed into establishing why and when third-parties report abuse and cooperate with the police, in comparison to the amount of research into victim reasons for reporting abuse (Felson et al., 2002). 
In summary, previous literature has associated victim cooperation and evidence gathering with successful prosecutions and a method in which more prosecutions can be delivered. This paper explores the extent to which cooperative individuals affect the likelihood of charging and prosecuting a suspect in response to intimate partner abuse. The study extends the focus on victim cooperation to examine other actors associated with the offence including the suspect, children, and associated witnesses. Based upon the previous literature, it is hypothesised that the likelihood of suspect charging will be greater in cases involving: victim cooperation; witness cooperation; suspect admission; the involvement of children; and the presence of physical evidence.

\section{METHOD}

The study used a quantitative approach to analyse a total of 540 cases of intimate partner abuse, recorded by a police force in the North of England. A stratified convenience sampling method was used to source the 540 partner abuse cases. The sample was stratified to collect an equal number of cases that resulted in a charge against the suspect and no charge against the suspect, which formed the dependent variable. After splitting the overall sample on the police database, the first 270 cases of each type were selected for convenience. The sample focused on cases that occurred between $1^{\text {st }}$ January $-31^{\text {st }}$ March 2013 with both paper-based casefiles (that had not yet been electronically recorded) and electronic casefiles being used in the study. As the study only accessed police data, no information was collected on the court outcome of each case. This was because, at that time, each case would have needed to be followed up with the Crown Prosecution Service (CPS) to determine the outcome at court. Therefore, the dependent variable of the analysis, and overall remit of the study, was the charging decision against the suspect. The main documents used in data collection were the MG3 (Charging Decision), MG5 (Incident Report) and MG11 (statements from all parties involved). The documents included important data on the details of each case, including information on all parties involved (The Prosecution Team, 2011). 
Information on victim engagement, witness engagement, suspect admission, and the involvement of children were all collected as they could be reliably coded across all cases, and related to actors that could have impacted upon the progression of the case. The presence of physical evidence was also coded as it was considered an important control variable within an analysis of suspect charging. Dichotomous coding was used to maximise clarity and reliability when extracting the data from police case files (Almond \& Canter, 2007). Victim engagement was considered as either cooperation (1) or withdrawal (0) within each case and, as part of the inclusion criteria, there was at least one victim per case $(n=540)$. Of the 540 cases, there were 345 cases of victim cooperation $(63.9 \%)$ and 195 cases of victim withdrawal $(36.1 \%)$. The study was unable to determine whether victims coded as cooperative attended court. This meant that the coding of engagement was only applicable to the police investigation and charging decision within each case. Furthermore, victims who stated they would cooperate with all elements of the police response, but did not want to attend court to testify, were also coded as cooperative as they were fully engaged with the police investigation of abuse.

Witness engagement was considered as a dichotomous outcome. For the purposes of the study, a witness was defined as any third-party (persons other than the victim, suspect, and attending officers) who were in some way involved in the abuse incident. There were 249 cases that involved at least one witness; however, the variable was coded (1) for those who cooperated with the police investigation $(n=197,36.5 \%)$, with the remaining cases coded as not present/uncooperative (0).

Suspect admission was coded as either present (1) or not present (0) within each case. This was determined from the police report of the suspect interviews. The admission was recorded as present whenever the suspect provided a partial or full admission to a crime for which they were arrested. An admission was coded as not present when the suspect answered no comment, provided a counter-narrative/allegation, or was too aggressive for interview. In total, a full or partial admission was made in 236 cases (43.7\%).

Any child under the age of 16 and in the care of either the suspect, the victim, or both was examined within the study. They were coded as either present (1), or not present (0). Their 
involvement was usually as a witness to the abuse incident, visually or audibly, and were often distressed upon police arrival. Some cases also involved the child directly in the incident where they were subject to physical abuse, or indirectly injured during a physical assault. Across the 540 cases, at least one child was present in the incident in 143 cases $(26.5 \%)$.

Physical evidence was coded whenever there was evidence found, other than from the victim's account or the account made by the attending officers. Physical evidence included: forensic evidence; photos of injury and/or damage; body worn video footage; CCTV footage; mobile phone footage; social media and/or text message communication; and other case specific physical evidence. In total, 345 cases $(63.9 \%)$ involved some form of physical evidence.

The dataset was analysed using a binary logistic regression to determine to what extent the involvement of such parties could explain the charging of the suspect (Field, 2018).

\section{RESULTS}

Binary logistic regression investigated the likelihood of a charge against the suspect (1) compared to no charge against the suspect (0), based on the influence of five explanatory variables. The five variables examined were: victim cooperation (present 63.9\%); witness cooperation (present 36.5\%); suspect admission (present 43.7\%); children involved (present 26.5\%); and physical evidence (present 63.9\%).

The calculation found a statistically significant model that explained between $15.3 \%$ (Cox and Snell $\mathrm{R}^{2}$ ) and $20.5 \%\left(\right.$ Negelkerke $\mathrm{R}^{2}$ ) of the variation in suspect charging, $X^{2}(540)=$ $89.987, p<.001$ (see Table 1). It correctly classified $65.9 \%$ of cases, an increase of $15.9 \%$ when compared to random chance (50\% correct classification). The model found that victim cooperation, witness cooperation, and physical evidence significantly increased the likelihood of suspect charging, whereas suspect admission significantly lowered the likelihood of suspect charging. 
Table 1: Logistic regression model for victim engagement, witness engagement, suspect admission, present children and physical evidence: Suspect Charged $(\mathrm{n}=270)$ vs No Charge $(n=270)$.

\begin{tabular}{lllll}
\hline Variable & $\beta$ & $\operatorname{Exp}(\beta)$ & \multicolumn{2}{c}{$\operatorname{Exp}(\beta) 95 \%$ CI } \\
& & & Lower & Upper \\
\hline $\begin{array}{l}\text { Victim } \\
\text { Cooperation }\end{array}$ & 0.874 & $2.397 * * *$ & 1.621 & 3.544 \\
$\begin{array}{l}\text { Witness } \\
\text { Cooperation }\end{array}$ & 0.863 & $2.370^{* * *}$ & 1.580 & 3.554 \\
$\begin{array}{l}\text { Suspect } \\
\text { Admission }\end{array}$ & -0.774 & $0.461 * * *$ & 0.317 & 0.670 \\
$\begin{array}{l}\text { Child Present } \\
\text { Physical }\end{array}$ & -0.400 & 0.671 & 0.437 & 1.028 \\
Evidence & 0.824 & $2.280^{* * * *}$ & 1.523 & 3.414 \\
Constant & $\mathbf{- 0 . 9 6 6}$ & $\mathbf{0 . 3 8 1 * * *}$ & & \\
\hline$* * * p<.001, * * p<.01, * p<.05$ & & & \\
\hline
\end{tabular}

Due to the results indicating that suspect admission had a negative relationship with suspect charging, the researchers further investigated the cases of no charge against the suspect. Upon examination, such cases appeared to result predominantly in a simple caution. Subsequently, a fresh variable of 'Case Outcome' was coded using the outcomes attached to the police casefiles, to further understand the dynamics behind no charge against the suspect $(\mathrm{n}=538)(0$ - No Further Action (NFA); 1 - Simple Caution; and 2 Charged/Court Disposal). Chi square analysis was then used to determine the relationship between suspect admission and the outcome of the case (see Table 2). The test found a statistically significant association between the variables that illustrated how cases of suspect admission were significantly more likely to result in a simple caution $(93.6 \%, \mathrm{n}=$ $132)$, in comparison to NFA $(5.5 \%, \mathrm{n}=7)$ and a court disposal $(35.6 \%, \mathrm{n}=96), X^{2}(2, \mathrm{n}=$ $538)=225.380, p<.001, V=.647$. 
Table 2: Chi square of Suspect Admission against No Further Action (NFA), a Simple Caution and Court Disposal (Charged).

\begin{tabular}{llll}
\hline & $\begin{array}{l}\text { Suspect Admission } \\
(\mathrm{n}=235)\end{array}$ & $\begin{array}{l}\text { No Admission } \\
(\mathrm{n}=303)\end{array}$ & $\begin{array}{l}\text { Total } \\
(\mathbf{n}=\mathbf{5 3 8})\end{array}$ \\
\hline $\begin{array}{l}\text { No Further Action } \\
\text { (NFA) }\end{array}$ & 7 & 120 & $\mathbf{1 2 7}$ \\
& $(3.0 \%)$ & $(39.6 \%)$ & \\
Simple Caution & 132 & 9 & $\mathbf{1 4 1}$ \\
& $(56.2 \%)$ & $(3.0 \%)$ & \\
$\begin{array}{l}\text { Court Disposal } \\
\text { (Charged) }\end{array}$ & 96 & 174 & $\mathbf{2 7 0}$ \\
\hline
\end{tabular}

*2 cases were missing as they had an outcome other than those coded, including a harassment order and a conditional caution.

\section{DISCUSSION}

There is considerable criticism surrounding the ability of criminal justice agencies to prosecute perpetrators of domestic abuse. Whilst at times warranted, it does little to explain how performance can be improved. Where recommendations are provided, they often suggest more of the same - to improve both victim cooperation and evidence gathering. This study has explored these factors in more detail, but further extended the analysis to involve all actors in cases of abuse, including the suspect, children and other witnesses.

It is clear from the literature review that the suspect is a critical actor in influencing the likelihood of a charge for a domestic abuse crime. He or she can refuse to cooperate or, in some cases, form a counter-narrative with the intention of providing a credible alternative explanation to the victim's statement. The analysis of this study found that suspect admissions were significantly associated with no criminal charge, which resulted in a simple caution rather than no further action or formal charging. The results could be an illustration of the simplistic 'schemas', 'street craft' work, or 'working rules' (Robinson et al., 2018) mentioned within literature, where officers provided a successful conclusion to 
the case with minimal time and resources. This may have included instances where the suspect admitted to a lesser crime to avoid liability for a more serious criminal action, such as admitting to criminal damage thereby avoiding assault allegations. Further research into the practice of cautions, and the extent to which they are used, would be crucial in understanding whether they are used effectively in cases of abuse. This is especially important when considering the comments by Westmarland et al. (2018, p.12), who explain how out of court disposals remain under-researched and that perpetrators may be operating "under the radar" of the criminal justice process. In police practice, the use of cautions in cases of 'minor' or 'first time' abuse may be an appropriate way of processing cases where the victim does not want a prosecution (Hare, 2006), but such disposals should not be used in cases that involve any form of coercive control. A recommendation for police practice, therefore, could be to explicitly record why the officer used an out of court disposal, and how this consideration was weighed against deprivation to the victim's liberty, dignity, equality, and physical integrity (Stark, 2012).

A further core finding of the analysis was how a cooperative victim increased the likelihood of suspect charging. In turn, victim withdrawal was associated with no further action against the suspect. Unlike Dawson and Dinovitzer (2001), who found cooperation cases were seven times more likely to result in a prosecution in the US, these findings show that cooperative victims were two and a half times more likely to result in a charge against the suspect. The results provide insight into why officers place so much emphasis on the victim to secure a successful prosecution, and why it is often considered the most important factor in suspect charging (O’Neal et al., 2015).

However, cases of victim withdrawal may require more attention to determine what positive action actually looks like for those involved. As explained by Hoyle and Sanders (2000), not all victims aim to prosecute the suspect, since their overarching aim is to become domestic abuse free. In some instances, victim withdrawal could be a manifestation of fear or a lack of control as the abuser restricts their free will (Stark, 2012). It would be particularly dangerous if cases of this nature are overlooked due to difficulties in securing a charge, since the lack of victim cooperation may well be an effective tactic used by the abuser within an overall pattern of coercive control (Barlow \& Walklate, 2018). 
Conversely, some victims may consider rational reasons when they decide to withdraw from the police investigation, as they perceive a criminal justice response to be more harmful to their situation (Hare, 2006). In these circumstances, such as worries about childcare or finance, having more flexible and rehabilitative responses to domestic abuse may help towards improving victim engagement. This is because a victim may be offered options that better empower them to become abuse free, thus the criminal justice system works to meet the victim's aim in each case (Birdsall et al., 2017). This could result in an increased level of satisfaction, confidence and perceived legitimacy for victims who do not seek a prosecution (Hoyle \& Sanders, 2000). The approach may help to build an overall response to victim retraction that encourages long term victim cooperation in future police responses. This in turn could subsequently ease the pressure on developing prosecutions that pursue the suspect without the victim's consent (Regoeczi \& Hubbard, 2018).

The results in this study found that there was no significant relationship between children and suspect charging. A cautious interpretation of the result could suggest that these cases have an added complexity that was not sufficiently captured within the current research. Therefore understanding 'how' children were involved may have provided more insight into their influence on the investigation. For example, cases where the child was directly involved may have been more likely to result in a charge against the suspect, especially if this involved physical abuse. The involvement of children may also have affected victim engagement. This could have taken the form of victim retraction in cases where social services were interacting with the victim, as the victim perceives the agencies to be working against their interests (Hines \& Douglas, 2009). However, child involvement may have also resulted in increased levels of victim cooperation if a victim considered the investigation and prosecution important to ensure the child's protection (Trepiccione, 2000). Unfortunately, the binary coding was insufficiently sophisticated to establish the contextual importance of the child's involvement and the wider impact this may have had on other actors within the case.

Across many jurisdictions there are initiatives that focus on controlling offender behaviour (Sechrist \& Weil, 2018) and prosecuting the suspect (Ellison, 2002) without the cooperation of the victim. In such approaches, other actors within the investigation become 
critical to the police investigation and charging decision. The results of the analysis found that witness cooperation appeared to have similar levels of influence as victim cooperation when both were examined against domestic abuse charging decisions. The finding highlights the importance of attempting to understand the reporting habits of third-parties in cases of domestic abuse, as the person reporting the abuse is likely to have witnessed some element of it. In such cases, their engagement and testimony should always be explored and encouraged to maximise the likelihood of a charge against the suspect. This is an important finding given that cooperative witnesses were present in several cases where the victim did not want to cooperate with the police investigation. In such instances, the presence of witnesses could have provided practical and emotional support for the victim, resulting in a stronger support network (Liang et al., 2005). Taking account of the dynamic explained by Barret and Hamiliton-Giachritsis (2013), the added support may allow for the aggrieved partner to prioritise their needs as a victim, as opposed to their requirements as a witness. This would then allow for a response that is likely to result in reduced trauma (Barrett \& Hamilton-Giachritsis, 2013). Subsequently, a future approach in police practice could look to assess victim engagement at the very beginning of the police investigation and explicitly record this as part of a risk assessment. This practice would seek to identify cases of victim withdrawal as early as possible, so officers can knowingly develop the investigation in the direction of a victimless prosecution. Because this determination is made at the initial scene, efforts can be made from the beginning of the investigation to seek out additional evidence, speak to neighbours to gain their perspective, and talk to friends and family of the victim to gain an understanding of the context of the relationship.

Finally, the presence of physical evidence gathered by the police was also a factor that increased the likelihood of suspect charging, with such cases being two times as likely to result in a prosecution. It is important to note that effective evidence collection could have been due to victim cooperation, or from present and cooperative witnesses providing statements (Hamby et al., 2016). However, the smaller likelihood odds ratio reported in the results section suggested that there were evidential difficulties in some cases that involved this variable. The results illustrated how the police attended a wide range of domestic abuse 
incidents, whereby evidence collection appeared to focus predominantly on photos of physical assault (Hoyle, 1998). Yet, within the current study, such evidence appeared to be weak in instances where the suspect provided a narrative that accounted for the physical evidence. Consequently, police and prosecutors were often left with two different accounts for the physical evidence gathered at the scene and the injuries sustained by all parties. The effective counter-narrative appeared to cause difficulty in progressing some cases of abuse and resulted in an outcome of no further action. However, cases where the suspect provided a poor account of the circumstances, or were disproved by other forms of evidence, appeared more likely to receive a charge (Hartley, 2001). Overall, suspect interaction appeared more complex than originally anticipated, since cases of non-admission seemed to result in a 'hit or miss' outcome of either a successful charge or no further action. In contrast, admissions were more likely to result in police cautions.

Taking the results into account, future research should examine the effectiveness of different evidence types whilst controlling for the suspect's counter-narrative or counterallegations within domestic abuse investigation. This is because the perpetrators most likely to form effective counter-narratives are those who are repeat abusers, or perpetrators who are well versed in coercive control. In turn, this could make them ever more dangerous as they are able to operate under the radar of the criminal justice system (Westmarland et al., 2018). In response, officers could become more detailed in their collection of evidence, such as the use of body worn video to record the abuse scene and key objects (Ellis et al., 2015). This evidence could be used to discredit the suspect's version of events after they have provided a counter-narrative in their interview.

\section{Limitations}

The study provided an analysis into the influence of actors in domestic abuse suspect charging; however, the study suffered from some key limitations. Firstly, the coding of the variables largely examined the presence and cooperation of the actors involved, which lacked detail on 'how' they impacted upon the investigation. Further research using a qualitative methodology may be better placed to understand the nuances, interactions and dynamics occurring between the various actors. Forming a more detailed understanding 
into how each actor influences the progression of the case could allow for more direct recommendations to be made to police practice that better addresses suspects, witnesses, children and victims.

Secondly, the data was sourced from cases that occurred in 2013. Since then, there have been several improvements to the police response to abuse in England and Wales. Whilst practical improvements include officer training and greater emphasis on the protection of children (HMICFRS, 2017), there has also been an expansion of the legislative response. The introduction of coercive control as a criminal offence in 2015 highlights the reprioritisation of efforts to tackle the underlying manipulation and fear behind abuse incidents, as opposed to responding to each violent manifestation of this control (Stark, 2012). More recently, a new domestic abuse bill is undergoing consideration within the UK parliament. One of the core elements of this bill is to strengthen numerous provisions for victims of abuse, as well as to establish a domestic abuse commissioner to advocate for victim rights. Notwithstanding the changes made to the domestic abuse response, Kirby (2013) illustrates how the police often face difficulty when attempting to implement suggested improvements into effective police practice. This difficulty extends to officers applying new legislation in practice, where only 1,157 cases of coercive control (from 7,034 arrests) resulted in a successful charge in the first three years of its implementation (Cowling, 2018). Consequently, although the results of the analysis are based upon a 2013 sample, it is likely that they will continue to be robust and reflective of the influence actors have in the charging of a suspect. However, updated research examining actors in abuse cases would be important to confirm whether the current findings remain applicable to recent cases of abuse.

\section{Conclusion}

The criminal justice system is regularly criticised for not successfully prosecuting more suspects of domestic abuse. Often, suggestions to improve the criminal response relate to victim cooperation or enhanced evidence gathering, albeit with little illustration as to how this can be improved. The UK has shown that pressure on the police to record more domestic abuse cases has resulted in proportionately fewer prosecutions, due to 'evidential 
difficulties' being present. This study has examined the factors involved with successful prosecutions and has discovered, aside from victim cooperation and the presence of physical evidence, other actors have an important influence on the outcome of the case. Whilst exploring the role of victims, suspects and children, the article also highlights the importance of other witnesses at the scene, who can play a core role in successful case outcomes.

As such, it is argued that future research could focus on understanding the dynamics of third-party reports to understand who (i.e., family, friends, neighbours or independent witnesses) are the most effective, as well as when and why they are likely to report abuse. The use of witnesses as advocates may improve the investigation of domestic abuse cases and remove the burden of prosecution from victims (Ellison, 2002). The police could also introduce the explicit recording of victim engagement within risk assessments conducted at the initial scene. Identifying victim withdrawal from the very beginning could allow officers to conduct enhanced evidence gathering and witness interviews, with the aim of maximising the option for a victimless prosecution. In addition, the use of simple cautions in domestic abuse cases would need critical further research. It is important to determine whether out of court disposals are being used to achieve victim satisfaction and confidence, or to achieve a quick resolution of the case (Westmarland et al., 2018).

\section{REFERENCES}

Almond L and Canter D (2007) Youths who sexually harm: A multivariate model of behaviour. Journal of Sexual Aggression 13(3): 217-233.

Barett E and Hamilton-Giachritsis C (2013) The victim as a means to an end: Detective decision making in a simulated investigation of attempted rape. Journal of Investigative Psychology and Offender Profiling 10(2): 200-218. 
Barlow C and Walklate S (2018) Policing intimate partner violence: The 'golden thread' of discretion. Policing: A Journal of Policy and Practice 1-10. DOI: 10.1093/police/pay001.

Belknap J, Hartman J and Lippen V (2010) Misdemeanor domestic violence cases in the courts: A detailed description of the cases. In: Garcia V and Clifford J (eds) Female victims of crime: Reality reconsidered. Columbus, OH: Prentice Hall, pp.259-278.

Birdsall N, Kirby S and McManus M (2017) Police-victim engagement in building a victim empowerment approach to intimate partner violence cases. Police Practice and Research 18(1): 75-86.

Callaghan J, Joanne A, Sixsmith J and Fellin L (2018) Beyond “witnessing”: Children's experiences of coercive control in domestic violence and abuse. Journal of Interpersonal Violence 33(10): 1551-1581.

Carey C and Solomon R (2014) Impossible choices: Balancing safety and security in domestic violence representations. Clinical Law Review 21(1): 201-254.

Cook S and Goodman L (2006) Beyond frequency and severity: Development and validation of the brief coercion and conflict scales. Violence Against Women 12(11): 1050-1072.

Cowling R (2018) Domestic abuse: Majority of controlling cases dropped. BBC News, 4 December, 2018. Available at: https://www.bbc.co.uk/news/uk-46429520 (accessed 28 April 2020).

Crown Prosecution Service (2017) Victims and witnesses. Available at: www.cps.gov.uk/victims_witnesses/reporting_a_crime/decision_to_charge.html (accessed 20th June 2019)

Davis R, Smith B and Taylor B (2003) Increasing the proportion of domestic violence arrests that are prosecuted a natural experiment in Milwaukee. Criminology and Public Policy 2(2): 263-282. 
Dawson M and Dinovitzer R (2001) Victim cooperation and the prosecution of domestic violence in a specialised court. Justice Quarterly 18(3): 593-622.

Dawson M and Holton T (2014) Police charging practices for incidents of intimate partner violence in Canada. Journal of Research in Crime and Delinquency 51(5): $655-683$.

Douglass A, Ray J, Hasel L and Donnelly K (2016) Does it matter how you deny it?: The role of demeanour in evaluations of criminal suspects. Legal and Criminological Psychology 21(1): 141-160.

Dutton M and Goodman L (2005) Coercion in intimate partner violence: Toward a new conceptualisation. Sex Roles 52(11-12): 743-756.

Eigenberg H, Kappeler V and McGuffee K (2012) Confronting the complexities of domestic violence: A social prescription for rethinking police training. Journal of Police Crisis Negotiations 12(2): 122-145.

Ellis T, Jenkins C and Smith P (2015) Evaluation of the introduction of personal issue body worn cameras (Operation Hyperion) on the Isle of Wight: Final report to Hampshire Constabulary. Report, University of Portsmouth, UK, February.

Ellison L (2002) Prosecuting domestic violence without victim participation. Modern Law Review 65(6): 834-858.

Fanslow J and Robinson E (2010) Help-seeking behaviours and reasons for help seeking reported by a representative sample of women victims of intimate partner violence in New Zealand. Journal of Interpersonal Violence 25(5): 929-951.

Felson R, Messner S, Hoskin A and Deane G (2002) Reasons for reporting and not reporting violence to the police. Criminology 40(3): 617-648.

Field A (2018) Discovering statistics using IBM statistics (5th edn). London: SAGE. 
Hamberger L, Larsen S and Lehrner A (2017) Coercive control in intimate partner violence. Aggression and Violent Behaviour 37: 1-11.

Hamby S, Weber M, Grych J and Banyard V (2016) What difference do bystanders make? The association of bystander involvement with victim outcomes in a community sample. Psychology of Violence 6(1): 91-102.

Hare S (2006) What do battered women want? Victims' opinions on prosecution. Violence and Victims, 21(5): 611-628.

Hartley C (2001) "He said, she said" the defense attack of credibility in domestic violence felony trials. Violence Against Women 7(5): 510-544.

Her Majesty's Inspectorate of Constabulary and Fire and Rescue Services (HMICFRS) (2017) A progress report on the police response to domestic abuse. London: HMICFRS.

Hines D and Douglas E (2009) Women's use of intimate partner violence against men: Prevalence, implications, and consequences. Journal of Aggression, Maltreatment \& Trauma 18(6): 572-586.

Hoyle C (1998) Negotiating domestic violence: Police, criminal justice, and victims. Oxford: Oxford University Press.

Hoyle C and Sanders A (2000) Police response to domestic violence. British Journal of Criminology 40(1): 14-36.

Johnson R and Dai M (2016) Police enforcement of domestic violence laws: Supervisory control or officer prerogatives? Justice Quarterly 33(2): 185-208.

Jones A and Penrod S (2018) Improving the effectiveness of the Henderson instruction safeguard against unreliable eyewitness identification. Psychology, Crime \& Law 24(2): 177-193. 
Kelly U (2009) "I'm a mother first": The influence of mothering in the decision-making processes of battered immigrant Latino women. Research in Nursing \& Health 32(3): 286-297.

Kingsnorth R and MacIntosh R (2004) Domestic violence: Predictors of victim support for official action. Justice Quarterly 21(2): 301-328.

Kirby S (2013) Police Effectiveness? Implementation in Theory and Practice. London: Palgrave Macmillan

Liang B, Goodman L, Tummala-Narra P and Weintraub S (2005) A theoretical framework for understanding help-seeking processes among survivors of intimate partner violence. American Journal of Community Psychology 36(1-2): 71-84.

Lifschitz J (2004) Battered women syndrome and prosecution of domestic abuse and rape cases. Georgetown Journal of Gender and the Law 5(1): 149-165.

MacCormick A, Cohen I and Ashton S (2018) Modifying the 'how' of an arrest: Reducing the interacting effect of childhood exposure to intimate partner violence and parental arrest. Police Practice and Research: An International Journal. Epub ahead of print 3 January 2019. DOI: 10.1080/15614263.2018.1555479

Menaker T and Cramer R (2012) The victim as witness: Strategies for increasing credibility among rape victim-witnesses in court. Journal of Forensic Psychology Practice 12(5): 424-438.

Millar A, Devaney J and Butler M (2018) Emotional intelligence: Challenging the perceptions and efficacy of 'soft skills' in policing incidents of domestic abuse involving children. Journal of Family Violence. Available at: https://link.springer.com/article/10.1007/s10896-018-0018-9

Mills L (1998) Mandatory arrest and prosecution policies for domestic violence: A critical literature review and the cases for more research to test victim empowerment approaches. Criminal Justice and Behaviour 25(3): 306-318. 
Morrow W, Katz C and Choate D (2012) Assessing the impact of police body-worn cameras on arresting, prosecuting, and convicting suspects of intimate partner violence. Police Quarterly 19(3): 303-325.

Myhill A and Johnson K (2016) Police use of discretion in response to domestic violence. Criminology \& Criminal Justice 16(1): 3-20.

O’Neal E, Tellis K and Spohn C (2015) Prosecuting intimate partner sexual assault: Legal and extra-legal factors that influence charging decisions. Violence Against Women 21(10): 1237-1258.

Peckover S and Golding B (2017) Domestic abuse and safeguarding children: Critical issues for multiagency work. Child Abuse Review 26(1): 45-50.

Peled E and Gil I (2011) The mothering perceptions of women abused by their partner. Violence Against Women 17(4): 457-479.

Peterson R and Bialo-Padin D (2012) Domestic violence is different: The crucial role of evidence collection in domestic violence cases. Journal of Police Crisis and Negotiations 12(2): 103-121.

Porter A (2018) Prosecuting domestic abuse in England and Wales: Crown prosecution service 'working practice' and new public managerialism. Social \& Legal Studies, 28(4): 493-516.

Rauma D (1984) Going for gold: Prosecutorial decision making in cases of wife assault. Social Science Research 13(4): 321-351.

Regoeczi W and Hubbard D (2018) The impact of specialised domestic violence units on case processing. American Journal of Criminal Justice 43(3): 570-590.

Rhodes K, Dichter M, Kothari C, Marcus S and Cerulli C (2011) The impact of children on legal actions taken by women victims of intimate partner violence. Journal of Family Violence 26(5): 355-364. 
Robinson A and Cook D (2006) Understanding victim retraction in cases of domestic violence: Specialist courts, government policy, and victim-centred justice. Contemporary Justice Review: Issues in Criminal, Social, and Restorative Justice 9(2): 189-213.

Robinson A, Pinchevsky G and Gutherie J (2018) A small constellation: Risk factors informing police perceptions of domestic abuse. Policing and Society 28(2): 189204.

Robinson D, Smith-Lovin L and Tsoudis O (1994) Heinous crime or unfortunate accident? The effect of remorse on responses to mock criminal confessions. Social Forces 73, 175-190.

Schuller R and Stewart A (2000) Police responses to sexual assault complaints: The role of perpetrator/complainant intoxication. Law and Human Behaviour 24(5): 535-551.

Sechrist S and Weil J (2018) Assessing the impact of a focused deterrence strategy to combat intimate partner domestic violence, Violence Against Women 24(3): 243-265.

Sleath E and Smith L (2017) Understanding the factors that predict victim retraction in police reported allegations of intimate partner violence. Psychology of Violence 7(1): 140-149.

Stark E (2012) Looking beyond domestic violence: Policing coercive control. Journal of Police Crisis and Negotiations 12(2): 199-217.

Starmer K (2011) Domestic violence: The facts, the issues, the future. International Review of Law, Computers \& Technology 25(1-2): 9-15.

The Prosecution Team (2011) The prosecution team manual of guidance for the preparation, processing and submission of prosecution files. England: The Prosecution Team, ACPO and NPIA. 
Trepiccione M (2000) At the crossroads of law and social science: Is charging a battered mother with failure to protect her child an acceptable solution when her child witnesses domestic violence. Fordham Law Review 69(4): 1487-1522.

Tyler T and Fagan J (2008) Legitimacy and cooperation: Why do people help the police fight crime in their communities. Ohio States Journal of Criminal Law 6(1): 231276.

UNISON (2018) Drop in criminals facing court as police lack resources to investigate. Available at: https://www.unison.org.uk/news/ps-data/2018/08/drop-criminalsfacing-court-police-lack-resources-investigate/ (accessed 4 February 2019).

Westmarland N, Johnson K and MacGlynn C (2018) Under the radar: The widespread use of 'out of court resolutions' in policing domestic violence and abuse in the United Kingdom. The British Journal of Criminology 58(1): 1-16. 